\title{
Molar-Incisor Hypomineralization: A Challenge in the Dental Practice
}

\author{
Aline Borburema Neves, Roberta Costa Jorge, Joao Vitor Marien, Priscila Simoes and Vera Mendes Soviero*
}

Department of Preventive and Community Dentistry, Pediatric Dental Clinic, Faculty of Dentistry, Rio de Janeiro State University, Rio de Janeiro, Brazil

\begin{abstract}
Molar-incisor hypomineralization is a relatively prevalent qualitative enamel defect worldwide. Some factors have been associated with this condition, but its etiology remains unknown. Due to the impact in dental treatment needs, the knowledge of this enamel defect characteristics and predictors, as the presence of hypomineralization in second primary molars, can lead to an early and effective diagnosis.
\end{abstract}

Keywords: Dental enamel; Hypoplasia; Tooth abnormalities; Children

Abbreviations: MIH: Molar-Incisor Hypomineralization; DMH: Deciduous Molar Hypomineralization; EAPD: European Academy of Paediatric Dentistry

\section{Introduction}

Tooth development occurs via cellular and biochemical mechanisms and this multi-level, tridimensional and progressive process are influenced by genetic and environmental factors [1]. Enamel formation can be divided into two distantly but simultaneous stages. Matrix proteins are secreted in the initial phase, and the secondary stage involves mineralization and maturation [2]. Different developmental defects of enamel are related to the disturbance moment and its duration. Quantity defects, as hypoplasia, are resulted from alterations in secretion phase, while changes during mineralization and maturation results in normal thickness but hypomineralized enamel, which is a qualitative defect $[3,4]$.

In 2001, a qualitative enamel defect that affects one to all first permanent molars and can be frequently associated with affected incisors was defined as Molar-Incisor Hypomineralization (MIH) [5]. The main MIH clinical characteristics are demarcated opacities, posteruptive breakdown and atypical restorations [5]. When these same characteristics are observed in second primary molars, the condition is named Deciduous Molar Hypomineralization (DMH) [6-8].

According to the European Academy of Paediatric Dentistry (EAPD) policy, MIH can be classified as mild and severe depending on how extensive is the defect and on the complexity of the treatment need [9]. Mild MIH comprises demarcated opacities without breakdown and occasional tooth sensitivity, while severe MIH include post-eruptive enamel or enamel and dentine breakdown, restorations with atypical shape and extension, or even extractions due to MIH [9].

This is a relatively common condition around the world and its prevalence can range from 10 to $25 \%$ [10-13], although some prevalence surveys have found higher values $[14,15]$. Even though there are few studies about DMH prevalence, an occurrence from 4.0 to $9.0 \%$ has been reported $[7,8]$.

\section{Risk Factors and Predictors}

Despite of MIH etiology being still unclear [6], some factors have been associated with this enamel defect. As genetic and environmental factors can modify tooth development and hard tissues quality [16], some pre-, peri- and post-natal conditions such as problems during pregnancy, low birth weight and antibiotics intake during the first 3 years of life [16,17] could been considered as possible etiological factors. Several agents can act synergistically and enhance the risk of MIH occurrence [9].
The second primary molars can play an important role in $\mathrm{MIH}$ prediction. As second primary molars formation occurs concomitantly to permanent incisors and primary molars [18], exposition to possible etiological factors for MIH could also result in deciduous hypomineralization [19]. Studies have shown that the presence of DMH increases in 4.4 times the chance of the occurrence of MIH $[7,8]$. Thus, as second primary molars erupt three to four years before the permanent molars, DMH might be a relevant predictor to MIH [8], contributing to an early diagnosis and enabling a better conduction and follow up. Figure 1A-E shows an eight year-old boy with DMH and $\mathrm{MIH}$. Although DMH was mild, presenting only demarcated opacities in the lingual surface of tooth 55 (Figure 1B) and in the buccal and lingual surface of tooth 65 (Figure 1C), he presented severe MIH affecting the upper first permanent molars with demarcated opacities and the lower ones with enamel breakdown associated to clearly affected permanent incisors (Figure 1A-E).

\section{Clinical Implications}

Hypomineralized teeth often need restorative treatment due to post-eruptive breakdown and/or caries and children with MIH can present 10 times more dental requirement than others patients without this condition [20]. Dental treatment to MIH patients ranges from prophylactic strategies to high complexity procedures.

DMH and MIH are often associated with dental decay in second primary molars and first permanent molars, respectively [21]. The hypomineralized enamel, more porous and fragile, not only breaks but also seems to facilitate caries initiation and progression [22]. Whether by carious lesions or post eruptive breakdown, these teeth need restorative treatment and the choice of the restorative material depends on the extension and severity of the enamel defect [9].

Other relatively frequent condition in $\mathrm{MIH}$ patients is the presence of dental hypersensitivity [5], which can difficult obtaining an effective local anesthesia. Pain and discomfort during treatment often lead to behavior problems and dental anxiety in children with severe enamel hypomineralization [20].

${ }^{*}$ Corresponding author: Dr. Vera Mendes Soviero, Department of Preventive and Community Dentistry, Pediatric Dental Clinic, Faculty of Dentistry, Rio de Janeiro State University, Rio de Janeiro, Brazil, Tel: +55 21 2868-8637; E-mail: verasoviero@gmail.com

Received April 14, 2015; Accepted May 13, 2015; Published May 19, 2015

Citation: Neves AB, Jorge RC, Marien JV, Simoes P, Soviero VM (2015) MolarIncisor Hypomineralization: A Challenge in the Dental Practice. Dentistry 5: 307. doi:10.4172/2161-1122.1000307

Copyright: $\odot 2015$ Neves AB, et al. This is an open-access article distributed under the terms of the Creative Commons Attribution License, which permits unrestricted use, distribution, and reproduction in any medium, provided the original author and source are credited. 
Citation: Neves AB, Jorge RC, Marien JV, Simoes P, Soviero VM (2015) Molar-Incisor Hypomineralization: A Challenge in the Dental Practice. Dentistry 5: 307. doi:10.4172/2161-1122.1000307

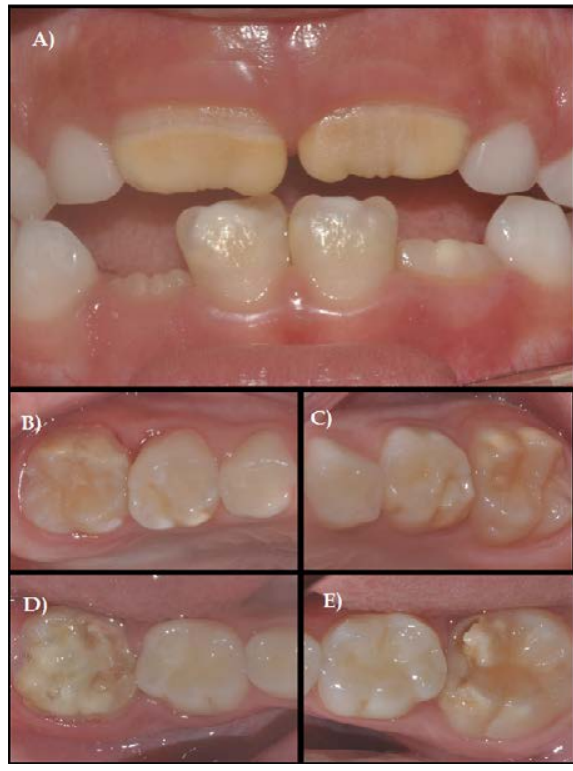

Figure 1: An eight years-old boy with $\mathrm{DMH}$ and $\mathrm{MIH}$. Demarcated opacities are seen in the lingual surface of tooth $55^{\star}(1 \mathrm{~B})$ and in the buccal and lingual surface of tooth $65^{*}(1 \mathrm{C})$. Severe $\mathrm{MIH}$ affects the upper first permanent molars with demarcated opacities $(B$ and $C$ ) and the lower ones with enamel breakdown ( $D$ and $E$ ). The upper permanent incisors are affected by yellowish opacities and the lower ones are affected by white opacities (A) (*FDI Dental Numbering System).

\section{Conclusion}

Given the impact on the dental treatment needs, MIH is considered a challenge in dental practice both for the dentist and the patient. Early diagnosis is important to prevent extensive enamel breakdown and severe complications due to MIH. As DMH has been considered a good predictor of $\mathrm{MIH}$, dentists should see children with $\mathrm{DMH}$ more often during the stage of eruption of the first permanent molars be aware of the characteristics and clinical implications of MIH.

\section{References}

1. Brook AH (2009) Multilevel complex interactions between genetic, epigenetic and environmental factors in the aetiology of anomalies of dental development. Archives of oral biology 54 1: S3-17.

2. Seow WK (2014) Developmental defects of enamel and dentine: challenges for basic science research and clinical management. Aust Dent J 59 Suppl 1: 143-154.

3. Simmer JP, Hu JC (2001) Dental enamel formation and its impact on clinical dentistry. J Dent Educ 65: 896-905.

4. Jalevik B, Dietz W, Noren JG (2005) Scanning electron micrograph analysis of hypomineralized enamel in permanent first molars. International journal of paediatric dentistry / the British Paedodontic Society [and] the International Association of Dentistry for Children 154:233-240.

5. Weerheijm KL, Jälevik B, Alaluusua S (2001) Molar-incisor hypomineralisation Caries Res 35: 390-391.

6. Weerheijm KL, Duggal M, Mejare I, Papagiannoulis L, Koch G, et al. (2003) Judgement criteria for molar incisor hypomineralisation $(\mathrm{MIH})$ in epidemiologic studies: a summary of the European meeting on MIH held in Athens, 2003.
European journal of paediatric dentistry : official journal of European Academy of Paediatric Dentistry 43:110-113.

7. Elfrink ME, Schuller AA, Weerheijm KL, Veerkamp JS (2008) Hypomineralized second primary molars: prevalence data in Dutch 5-year-olds. Caries Res 42 282-285.

8. Elfrink ME, ten Cate JM, Jaddoe VW, Hofman A, Moll HA et al. (2012) Deciduous molar hypomineralization and molar incisor hypomineralization. $J$ Dent Res 91: 551-555

9. Lygidakis NA, Wong F, Jalevik B, Vierrou AM, Alaluusua S, et al. (2010) Best Clinical Practice Guidance for clinicians dealing with children presenting with Molar-Incisor-Hypomineralisation (MIH): An EAPD Policy Document. European archives of paediatric dentistry : official journal of the European Academy of Paediatric Dentistry 112:75-81.

10. Shrestha R, Upadhaya S, Bajracharya M (2014) Prevalence of molar incisor hypomineralisation among school children in Kavre. Kathmandu Univ Med $J$ (KUMJ) 12: 38-42

11. Jeremias F, de Souza JF, Silva CM, Cordeiro Rde C, Zuanon AC, et al. (2013) Dental caries experience and Molar-Incisor Hypomineralization. Acta Odonto Scand 71: 870-876.

12. Ghanim A, Morgan M, Marino R, Bailey D, Manton D (2011) Molar-incisor hypomineralisation: prevalence and defect characteristics in Iraqi children. International journal of paediatric dentistry / the British Paedodontic Society [and] the International Association of Dentistry for Children 216:413-421.

13. Souza JF, Costa-Silva CM, Jeremias F, Santos-Pinto L, Zuanon AC, et al. (2012) Molar incisor hypomineralisation: possible aetiological factors in children from urban and rural areas. European archives of paediatric dentistry : official journal of the European Academy of Paediatric Dentistry 134:164-170.

14. Soviero V, Haubek D, Trindade C, Da Matta T, Poulsen S (2009) Prevalence and distribution of demarcated opacities and their sequelae in permanent $1 \mathrm{st}$ molars and incisors in 7 to 13-year-old Brazilian children. Acta Odontol Scand 67: $170-175$

15. Wogelius P, Haubek D, Poulsen S (2008) Prevalence and distribution of demarcated opacities in permanent 1st molars and incisors in 6 to 8 -year-old Danish children. Acta Odontol Scand 66: 58-64.

16. Laisi S, Ess A, Sahlberg C, Arvio P, Lukinmaa PL, et al. (2009) Amoxicillin may cause molar incisor hypomineralization. J Dent Res 88: 132-136.

17. Whatling R, Fearne JM (2008) Molar incisor hypomineralization: a study of aetiological factors in a group of UK children. Int J Paediatr Dent /the British Paedodontic Society [and] the International Association of Dentistry for Children 183:155-162

18. Butler PM (1967) Comparison of the development of the second deciduous molar and first permanent molar in man. Arch Oral Biol 12: 1245-1260.

19. Aine L, Backstrom MC, Maki R, Kuusela AL, Koivisto AM, et al. (2000) Ename defects in primary and permanent teeth of children born prematurely. Journal of oral pathology and medicine: official publication of the International Association of Oral Pathologists and the American Academy of Oral Pathology 298:403409.

20. Jalevik B, Klingberg GA (2002) Dental treatment, dental fear and behaviou management problems in children with severe enamel hypomineralization of their permanent first molars. Int J Paediatr Dent 121:24-32.

21. da Costa-Silva CM, Jeremias F, de Souza JF, Cordeiro Rde C, Santos-Pinto L et al. (2010) Molar incisor hypomineralization: prevalence, severity and clinical consequences in Brazilian children. Int J Paediatr Dent/the British Paedodontic Society [and] the International Association of Dentistry for Children 206:426434.

22. Elfrink ME, Schuller AA, Veerkamp JS, Poorterman JH, Moll HA, et al. (2010) Factors increasing the caries risk of second primary molars in 5-year-old Dutch children. Int J Paediatr Dent/the British Paedodontic Society [and] the International Association of Dentistry for Children 202:151-157. 